\title{
Medium term fluvial island evolution in relation with flood events in the Piave River
}

\author{
L. Picco ${ }^{1}$, L. Mao ${ }^{2}$, E. Rigon ${ }^{1}$, J. Moretto ${ }^{1}$, D. Ravazzolo ${ }^{1}$, \\ F. Delai ${ }^{1} \&$ M. A. Lenzi ${ }^{1}$ \\ ${ }^{1}$ Department of Land and Agroforest Environment, \\ University of Padova, Italy \\ ${ }^{2}$ Department of Ecosystems and Environment, \\ Pontificia Universidad Catolica de Chile, Santiago, Chile
}

\begin{abstract}
River islands could be defined as discrete areas of woodland vegetation surrounded by either water-filled channels or exposed gravel which exhibits some stability, and remain exposed during bunk-full flows. Islands are important from morphological, functional, and ecological points of view. The aim of the present study is to analyze the dynamics of stable, young and pioneer islands in the Piave River, which suffered intense and multiple human impacts especially due to dam building and in-channel gravel mining. Plan-form changes of river features from 1960 were analyzed using aerial photos, and a LiDAR was used to derive the maximum, minimum and mean elevation of island surfaces and the maximum and mean height of the island vegetation. The results suggest that stable islands lie at higher elevation than young and pioneer islands, and are characterized by a thicker layer of fine sediments deposited on their surfaces after big floods. There was a progressive decrease in the active corridor area from 1960 to 2006. After the 1966 exceptional flood (RI> 200 years) there was a moderate increase of island extend and numbers, followed by a further increase from 1991, due to a succession of flood events, in 1993 and 2002 with RI> 10 years, as well as a change in the anthropic management characterized by a control relating to mining activities. The narrowing trend (1960-1999) of the morphological plan-form, certainly enhanced the chance of the island to become stable and this explains the reduction of active channel, the increase of stable island and the reduction of pioneer island. Even though a general channel
\end{abstract}


widening is apparent in the study reached between 1999 and 2006, no clear indication of a widespread, concomitant aggradation phase is observed.

Keywords: river islands, gravel bed rivers, floods, Piave River, Italy.

\section{Introduction}

River islands could be defined as discrete areas of woodland vegetation surrounded by either water-filled channels or exposed gravel (Ward et al. [1]) which exhibits some stability (Osterkamp, [2]), and remains exposed during bank-full flow. Islands have the potential of enhancing the biodiversity within the riparian zone, because their shorelines are characterized by a mosaic of habitat patches of different age, level of disturbance and geo-morphological character, which are uncommon features along heavily managed river banks (Gurnell et al. [3]).

Since islands are separated from the floodplain, they may offer a safe haven for wildlife from many predators, and river management that reduces the total island area could for example have negative implications for migratory fowl. Arscott et al. [4] found that on the Fiume Tagliamento, aquatic habitat complexity was greater in the island-braided section as compared to the islanddevoid section. In the same river, Van der Nat et al. [5] showed that aquatic habitats were more stable in regions of vegetated islands even as compared to bar-braided regions. Stanford et al. [6] shown as islands are most likely to occur in areas of dynamic fluvial processes that would provide for high species diversity within a wide range of riparian habitat.

An early classification of straight, braided and meandering channel patterns (Leopold et al. [7]), implicitly incorporates island development through two different processes: a) the evolution of relatively stable medial bars on which vegetation can establish within braided channels; b) the isolation of section of vegetated floodplain through avulsion and cut-off along meandering channels. Kellerhals et al. [8] further discriminate between occasional, frequent, split and braided island patterns. The downstream changes in tree species, sediment, climate and subsurface hydrology dictate the strategies available for vegetation establishment and the rate at which the vegetation can develop. Islands can remain in place over decadal time scale, being defined as stable is resists after high flows. The type of islands present in a riverine system can help describe the river processes as well. Gurnell and Petts [9] determined that most European rivers were once island-dominated (pre-1900), but have become devoid of islands due to human interference. Away from areas of agricultural or urban development in Europe, islands remain a common feature of riverine landscapes, such as the Fiume Tagliamento in northeast Italy (Ward et al. [1]). The presence of a certain species of plant on the island can help determine the flow conditions in the area. Some plant species require specific growth conditions, such as inundation duration, gradient, and particle size.

Nearly all large rivers are flow-regulated to some degree. This can have implications for fluvial island development and stability. Dams reduce flood peaks, increase base flow, and store sediments (especially coarser material). The 
sediment transported past a dam can be only a fraction of the normal sediment load. The reduced flow peaks downstream of a dam eliminate most processes of channel erosion, overbank deposition, and sediment replenishment. This also generally reduces the biologic habitat, diversity, and interactions between biotic and hydrologic processes (Bathurst et al. [10]). While dams can reduce the erosion and destruction of fluvial islands, they also promote bank attachment by decreasing the sediment supply and reducing the downstream transport capacity which lead to deposition of tributary input sediment. Dams, however, can also be the cause of island development. The erosional flows downstream of a dam could scour around some centralized topography (Wyrick [11]).

Osterkamp [2] described several scenarios in which islands could disappear. Perimeter sediment deposition could eliminate an island by several methods. The first method is by preferential in-filling of one of the side channels that effectively raises the bed level in one anabranch but not the other, and thereby shifts the flow into a single path. The second method is by sedimentation around the whole perimeter of the island until it eventually coalesces with other nearby islands or the floodplain, again forcing the flow into a single path. A third method of island elimination is by the flow preferentially incising one of the side channels and leaving the other anabranch 'high and dry'. This is common downstream of dams after peak flows have been reduced. If a low flow regime persists for long enough, vegetation may accumulate between an island and its floodplain. The meandering nature of a river can cause it to laterally migrate and abandon one of the anabranches around an island. Floods can eliminate an island by two methods. The first is by simply increasing the flows to levels high enough that the entire island is eroded away. The second is by changing the main direction of the flow during a flood, thereby altering the angle of attack from the water and gradually wearing away the island by abrasion.

The aim of the present study is to study the dynamics of stable, young and pioneer island in the Piave River, which suffered intense and multiple human impacts especially due to dam building and in-channel gravel mining. The influence exerted by large floods and the importance of fine sediments deposited are also underlined.

\section{Study area}

The study has been conducted in the Piave River, which rises at an elevation of $2037 \mathrm{~m}$ a.s.l. and has a length of $222 \mathrm{~km}$. It flows from its source in the Dolomites to the Adriatic Sea (Fig. 1). The drainage basin is composed mainly of sedimentary rocks (predominantly limestone and dolomite) and has an area of $4500 \mathrm{~km}^{2}$. Morphologically, the course of the river can be divided into three reaches. The upper course, where the river is generally incised in bedrock and therefore has a quite narrow channel, extends from the source to Longarone. The middle course, where the river is very wide and characterized by a multithreaded channel pattern, extends from Longarone to Ponte di Piave. The lower course, where the river meanders but has been artificially straightened in places, extends from Ponte di Piave to the mouth (Surian [12]). The study reach (Fig. 1) is 


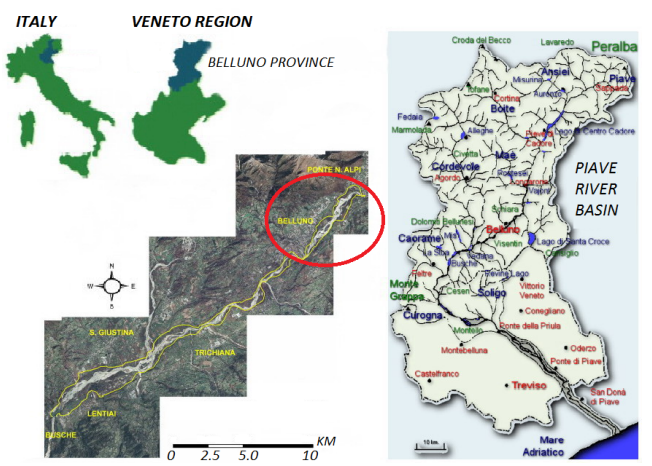

Figure 1: Location of the Piave river basin and the study reach; red circle indicate the smaller scale sub-reach analyzed.

$30 \mathrm{~km}$ long and is located along the middle course of the Piave River, within the mountain district. The average valley gradient is about $0.004 \mathrm{~m} \mathrm{~m}^{-1}$ and the bed width ranges from $100 \mathrm{~m}$ to $1000 \mathrm{~m}$. The study reach may be described as transitional between wandering and braided river. The median grain size varies between 20 and $50 \mathrm{~mm}$. The nearest flow recording site is located at Belluno. River plan-form changes and island evolution were study over the period 1960 2006. Large floods occurring during this period are listed in Table 1 (Da Canal, [13]). Within the study reach $(30 \mathrm{~km})$ another level of sub-reach $(5 \mathrm{~km})$ was then analyzed. The smaller scale of analysis consists of three different sub-reaches characterized, from upstream to downstream, by braiding, wandering and braiding morphology (Fig. 2). Both altimetrical characterization of the island ground and vegetation structure were carried out in each sub-reaches.

Table 1: $\quad$ Mainly flood events along the Piave River during the study period.

\begin{tabular}{|c|c|c|c|c|c|c|c|c|c|c|}
\hline Year & 1960 & 1965 & 1966 & 1976 & 1978 & 1980 & 1993 & 1998 & 2000 & 2002 \\
\hline $\mathrm{Q}(\mathrm{m} 3 / \mathrm{s})$ & 1605 & 2599 & 4091 & 1456 & 1419 & 1565 & 1752 & 1300 & 1282 & 1775 \\
\hline $\mathrm{RI}$ & 9.5 & 43 & 280 & 7.4 & 6.9 & 8.9 & 12.1 & 5.7 & 5.5 & 12.5 \\
\hline
\end{tabular}

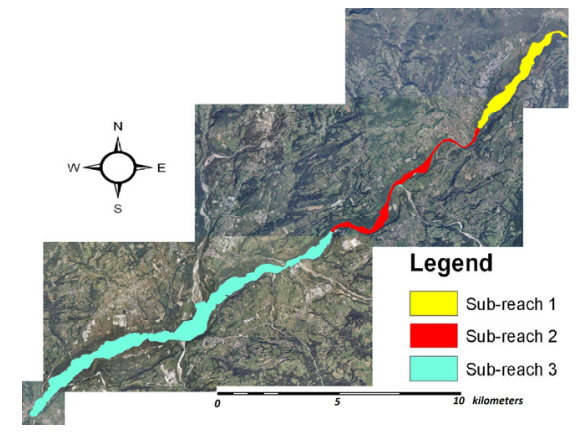

Figure 2: $\quad$ Location of the 3 sub-reaches analyzed. 


\section{Materials and methods}

Planform changes of river features over the last 60 years were analyzed using six aerial photos collected in 1960, 1970, 1982, 1991, 1999, and 2006. The aerial photos range in scale from 1:8.000 to $1: 33.000$. Photos were scanned at a resolution of $600 \mathrm{dpi}$ in order to obtain an average virtual resolution of $1 \mathrm{~m}$ or smaller. Aerial photographs were rectified and co-registered to a common mapping base at 1:5.000 by GIS software (Esri ArcGIS 9.2). Approximately 30 ground-control points were used to rectify each single frame, and second order polynomial transformations were then applied, obtaining root mean square errors (RMSE) ranging from 2 to $4 \mathrm{~m}$. The active channel area and width were calculated using the different aerial photographs and correspond to the area of water and un-vegetated sediment bars.

Assuming the conceptual model of island dynamics proposed by Edwards et al. [14], vegetated bars and pioneer islands were differentiated, being the latter areas with vegetation higher than $3 \mathrm{~m}$. Pioneer, young and stable islands were distinguished based on the maturity and size of the vegetation (Kollman et al. [15]). Canopy height derived from the LiDAR was used as a complement to aerial photographs (Zanoni et al. [16]). In the aerial photos, distinction between arboreal and shrubby vegetation was made estimating vegetation height based on canopy texture, shape and shadows. Pioneer islands were defined as surfaces on bars with patchy vegetation cover with spots of vegetation 3-5 m high; young islands, which are intermediary step towards the consolidation as established island, were distinguished because of the higher extension and ground elevation; stable island were instead defined as older (15-20 years) areas with a high dense vegetation cover (Gurnell and Petts, [9]). In a natural braided gravel bed river, these landforms rarely survive more than 20 or 25 years (Gurnell et al. [3]). Vegetation height was estimated using the vegetation cover information derived from a LiDAR flight of 2003. Based on the $1 \mathrm{~m}$ LiDAR resolution the raster subtraction of the original DTM layer and the DSM layer generated the Canopy Height Model, which was used to obtain the maximum, minimum and mean elevation of island surfaces and the maximum and mean height of the island vegetation (Picco et al. [17]).

\section{Results}

The active corridor area on the Piave River study reach increased from $13.4 \mathrm{~km}^{2}$ in 1960 to $14.2 \mathrm{~km}^{2}$ in 1970 , likely as a result of the exceptional flood of 1966 , and then decreased substantially until 1991 reaching $9.3 \mathrm{~km}^{2}$. Afterwards, the active corridor area increased gradually, reaching $10.6 \mathrm{~km}^{2}$ in 2006 . Within the active corridor area, the dynamics of island extent showed complex tendencies. Stable islands decreased from 1960 to 1970 (1.6 to $1.5 \%$ of the active corridor area), then increased up to $4.1 \%$ in 1982 , fluctuating afterwards around $3 \%$ and becoming lower only in 2006 (Fig. 3). Interestingly, considering their number, stable island remained around 2 to 2.5 per $\mathrm{km}^{2}$, with a substantial increase from 1999 to 2005, reaching 5.3 per $\mathrm{km}^{2}$ (Fig. 3). 

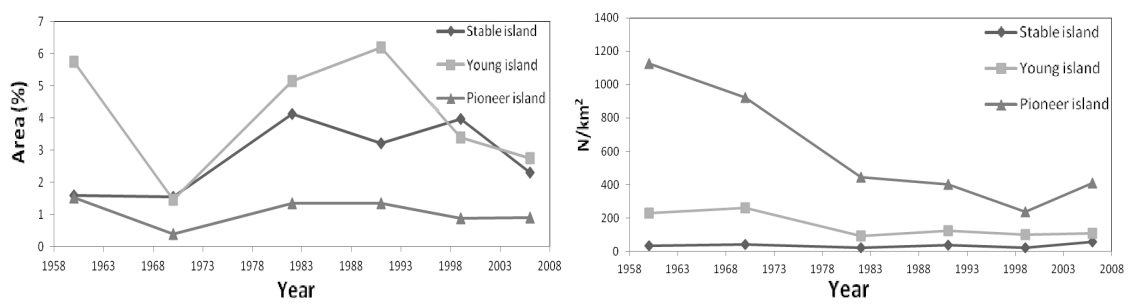

Figure 3: Extent of islands in the Piave River, expressed on terms of percentage as respect to the active corridor area (left) and $n^{\circ}$ per $\mathrm{km}^{2}$ (right).

Young islands show a similar tendency, with a strong decrease from 1960 $(5.7 \%)$ to $1970(1.5 \%)$ and then a substantial increase until $1991(6.2 \%)$, followed by a strong decrease until 2006 (2.8\% of the active corridor area). In terms of number of young island per $\mathrm{km}^{2}$, this decrease substantially from 1970 to 1982 (18.5 to 8.3), with a significant expansion period up to 1991 (13.4 young island per $\mathrm{km}^{2}$ ). Finally, the extent of pioneer island decreased from 1960 to $1970(0.4 \%)$, and than increased phase until $1991(1.4 \%)$ with a final contraction phase until $2006(0.9 \%)$. In this case, the number of pioneer islands per $\mathrm{km}-2$ decreased constantly from 1960 to 1999 (83.8 to 25.3), with a final expansion trend up to 2006 (38.4).

There is no significant change in the active channel surface along the subreach 1 , remaining quite constant over time. For the sub-reach 2 , there was a slight and constant decrease until 1991, followed by constant trend between 1960 and 1970. From 1991 to 2006 there was a new slow increase in the active area. Sub-reach 3 denotes a strong change over the study period under consideration. In fact, after a moderate increase phase from 1960 to 1970, there was a strong and continuous decrease period until 1991, with a stable trend from 1991 to 2000, and a new increase phase from 2001 to 2006.

Along the sub-reach 1 , there was a very low presence of "Stable islands" till 1982. Afterwards there was a quite strong increase in islands extent to the maximum value recorded in 1999 (5.6\%) followed by a new decrease in 2006 (3.8\%) (Fig. 4a).

Considering the "Young island" there was a decrease between 1960 (2.7\%) and $1970(0.5 \%)$, a subsequent increase to the maximum value recorded in 1991 $(8.5 \%)$, and another contraction phase."Pioneer island" represent a very limited area during the entire period under analysis. According to the analysis into figure 4 , analysing the number of the different types of islands normalized to the active channel area, a substantial stability of "Stable island" until the recent increase (15.4 $\mathrm{N} \mathrm{km}^{-2}$ ) can be observed. Instead, with regards to "Young island", these decreased between 1960 and 1982, subsequently increased until 1991 (25.2 N $\mathrm{km}^{-2}$ ), then decreased until $1999\left(15.6 \mathrm{~N} \mathrm{~km}^{-2}\right)$, with a very slight recent increase in 2006. "Pioneer island" show a noticeable increase between 1960 and 1970, followed by a sudden decrease until $1982\left(53.2 \mathrm{~N} \mathrm{~km}^{-2}\right)$ and a new increase until $1991\left(\mathrm{~N} \mathrm{~km}^{-2}\right)$. 
a)

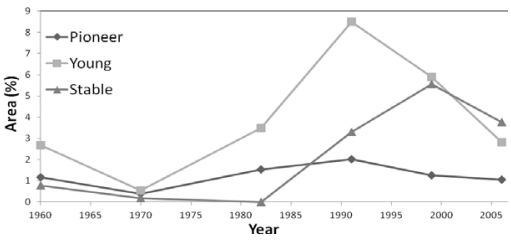

b)

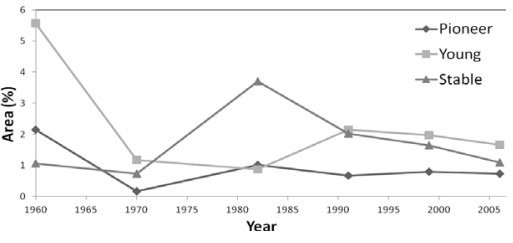

c)

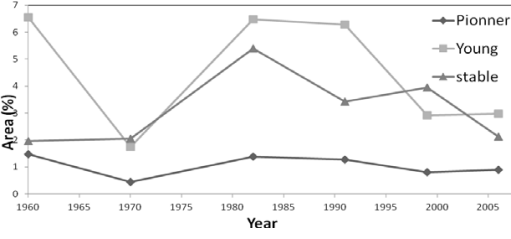

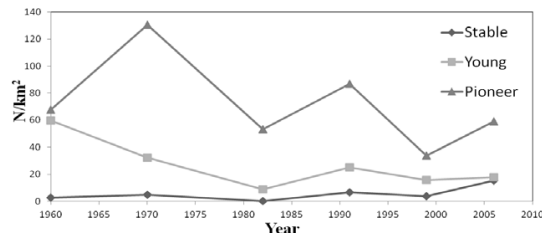
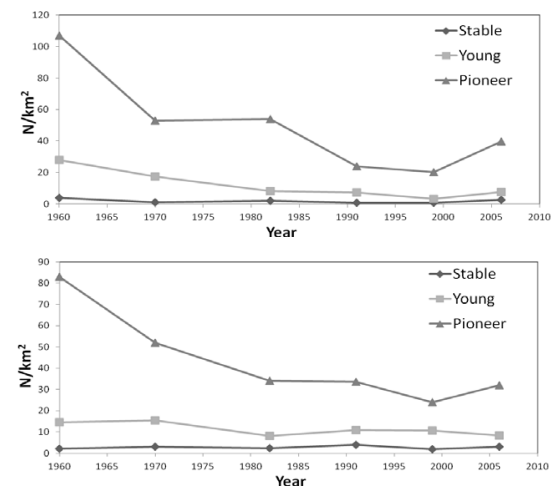

Figure 4: Extent of islands in the sub-reach 1 (a), sub-reach 2 (b) and subreach 3 (c), expressed on terms of percentage as respect to the active corridor area (left) and $\mathrm{n}^{\circ}$ per $\mathrm{km}^{2}$ (right).

Along the sub-reach 2 "Stable island" has decreased from 1960 (1.1\%) to $1970(0.7 \%)$, then has increased up to the maximum value in $1982(3.7 \%)$ (Fig. 4b). "Young island" has decreased from 1960 (5.6\%) to $1970(1.2 \%)$, then there was a slow-decrease period until 1980 (0.9\%). After that period, there was another increase phase until $1991(2.1 \%)$ and a subsequent slow and constant decrease period until $2006(1.7 \%)$. "Pioneer island" has got a constant trend fluctuating around lower values until.

"Stable island" has decreased from $1960\left(3.9 \mathrm{~N} \mathrm{~km}^{-2}\right)$ to $1970\left(0.9 \mathrm{~N} \mathrm{~km}^{-2}\right)$, after that there was an increase period until $1982\left(2.1 \mathrm{~N} \mathrm{~km}^{-2}\right)$; subsequently there was a decrease phase until $1999\left(0.8 \mathrm{~N} \mathrm{~km}^{-2}\right)$ and a final strong increase until 2006 (2.7 $\mathrm{N} \mathrm{km}^{-2}$ ) (Fig. 4b). "Young island" decreased between 1960 (28.0 $\left.\mathrm{N} \mathrm{km}^{-2}\right)$ and $1999\left(3.1 \mathrm{~N} \mathrm{~km}^{-2}\right)$ and then increased until $2006\left(7.5 \mathrm{~N} \mathrm{~km}^{-2}\right)$. "Pioneer island" has greatly decreased from $1960\left(107.0 \mathrm{~N} \mathrm{~km}^{-2}\right)$ to 1999 (20.2 $\left.\mathrm{N} \mathrm{km}^{-2}\right)$, followed by an increase phase until $2006\left(39.6 \mathrm{~N} \mathrm{~km}^{-2}\right)$.

Along the sub-reach 3 regarding the "Stable island" there was a constant trend between $1960(2.0 \%)$ and $1970(2.0 \%)$, followed by an increase up to the maximum value recorded in $1982(5.4 \%)$, then there was a progressive decrease until 2006 (2.1\%), with a sole value showing an opposing trend in 1999 (4.0\%) (Fig. 4c). Regarding "Young island" there was a fluctuating trend with a decrease between $1960(6.6 \%)$ and 1970 (1.7\%), an increase phase until 1982 $(6.5 \%)$, a stable phase until $1991(6.3 \%)$ and a final decrease phase until 2006 $(3.0 \%)$. 
"Stable island" shown continuous fluctuation between similar values, reaching the maximum in $1991\left(4.1 \mathrm{~N} \mathrm{~km}^{-2}\right)$ and the minimum in $1999(1.9 \mathrm{~N}$ $\mathrm{km}^{-2}$ ) (Fig. 4c). "Young island" has increased from $1960\left(14.6 \mathrm{~N} \mathrm{~km}^{-2}\right)$ to 1970 $\left(15.4 \mathrm{~N} \mathrm{~km}^{-2}\right)$, followed by a strong decrease phase until $1982\left(8.1 \mathrm{~N} \mathrm{~km}^{-2}\right)$, then there was a moderate increase up to $1991\left(11.0 \mathrm{~N} \mathrm{~km}^{-2}\right)$ and a subsequent slow and constant decrease phase until $2006\left(8.5 \mathrm{~N} \mathrm{~km}^{-2}\right)$. "Pioneer island" has decreased from $1960\left(82.9 \mathrm{~N} \mathrm{~km}^{-2}\right)$ to $1999\left(23.9 \mathrm{~N} \mathrm{~km}^{-2}\right)$ then has increased up to $2006\left(32.0 \mathrm{~N} \mathrm{~km}^{-2}\right)$.

In 2003,317 islands were present within the study reach, $75 \%$ of which were pioneer, $17 \%$ young, and $8 \%$ stable islands. Using the DTM obtained from the LiDAR flight, the elevation of island surfaces were derived, and their extent is depicted in figure 5. It shows that, surprisingly enough, the median value of the elevation of the three types of islands does not differ substantially. However, the stable islands feature mean elevations up to $3 \mathrm{~m}$, and most values range from 1 to around 1.5 meters, whereas young and pioneer islands show most of the mean elevation at lower values $(0.5 \mathrm{~m}-1.2 \mathrm{~m})$, and the highest islands of these 2 types are at around $2 \mathrm{~m}$ (excluding outliers for young type up to $2.5 \mathrm{~m}$ ).

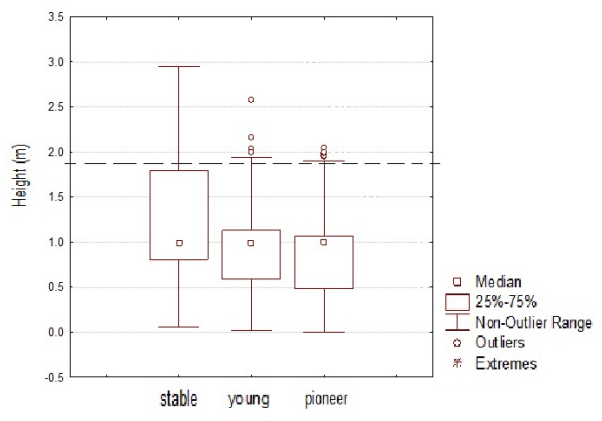

Figure 5: The elevation of three types of islands, in 2003, relative to the low flow water elevation. The dashed line represents the mean elevation of the floodplain.

Looking at the maximum ground elevation within each island (Fig. 5), stable islands are apparently "higher" than young and pioneer ones. In fact, they feature values up to $4 \mathrm{~m}$ and a median of $2 \mathrm{~m}$. Young and pioneer islands instead feature a median value of $1 \mathrm{~m}$ and a maximum of $3 \mathrm{~m}$. Most young and pioneer islands highest elevation lies between 1 to $2 \mathrm{~m}$. The mean elevation of the floodplain equal to $1.81 \mathrm{~m}$., is higher than all island (excluding outliers).

Figure 6 shows the maximum vegetation height in the different type of islands, as derived from the canopy analysis carried out using LiDAR data collected in 2003. It is evident that stable islands features the highest vegetation cover (median value around $17 \mathrm{~m}$ ), with maximum height around $25 \mathrm{~m}$. Young islands feature instead a median maximum height around $7 \mathrm{~m}$, with most of the values ranging from $5 \mathrm{~m}$ to $12 \mathrm{~m}$. Pioneer islands feature a median max height of about $2.5 \mathrm{~m}$, and maximum values (excluding outliers) of about $7 \mathrm{~m}$. Interestingly, the 
three types of islands are substantially different in terms of thickness of fine sediments deposited on their surfaces (as measured in the field). Being the older surfaces and featuring very stable vegetation cover, stable islands are able to trap a large amount of sand with thickness up to $1 \mathrm{~m}$ (Fig. 6).
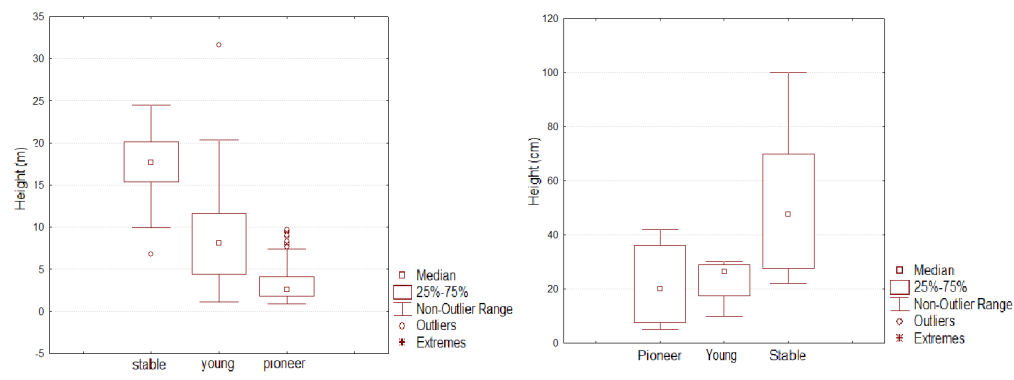

Figure 6: The maximum height of vegetation (on the left) and the thickness of fine sediments (on the right) on stable, young and pioneer islands in 2003.

Figure 7 shows the relationship between tree heights and tree ages for different species. A substantial constancy about the distribution of the different species is observed; only the Alnus tree present values not in agree with all others. The oldest tree found during field survey was a Populus tree of about 33 years old.

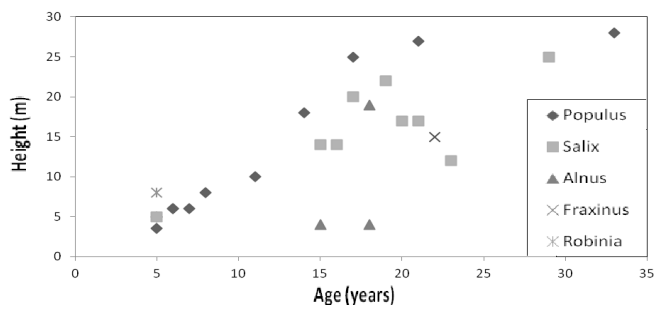

Figure 7: Relationship between tree heights and tree ages for different species.

\section{Discussion and conclusions}

According to the analysis of fluvial islands along the Piave River, the results show that there was a predominant and progressive decrease in the active corridor area from 1960 to 2006. After the 1966 exceptional flood there was a moderate increase of islands extent and number, followed by a further increase from 1991, due to a succession of flood events, in 1993 and 2002 with recurrence interval of 12 years for both, as well as a change in the anthropic management characterized by a control relating to mining activities [18, 19]. Stable islands increased from 1970 to 1982 due to a stability period that 
corresponds to a decrease in the active corridor area. Subsequently, there was a decrease in their percentage area because stable islands presumably merged with the floodplain vegetation. Instead, the flood event occurred in 1993, with recurrence interval of 12 years, caused a new increase of stable islands, till 1999, which is attributable to the reactivation of abandoned secondary channels, and thus to the detachment of stable portion of riparian vegetation from the floodplains. In this case an increase in the percentage surface is not always related to an increase in island number, and this is mainly due to the formation of "macro-islands". This occurs because close islands tend to merge through the transition of part of younger islands to other classes and/or the opening of new channels in the floodplain. Both the surface extent and the number of pioneer islands decreased until 1970 after the 1966 flood. Subsequently, as regards the area, there was an increase and a constant trend until 1991 due to low flood events occurred and a decrease until 1999 due to a succession of flood events, the most significant in 1993 with recurrence interval of 12 years. As expected, stable islands lie at higher elevation and are characterized by thicker layer of fine sediments deposited on their surfaces than young and pioneer islands. This is due to the fact that older vegetation growing on stable islands allows the deposition of fine sediments which, in turns, enhances the conditions for vegetation growing, providing even better conditions for the vegetation to establish on stable islands. As to the vegetation height, there is a clear differentiation between the three types of islands. The data obtained analyzing the LiDAR data are confirmed by field surveys. Also, a dendrocronological analysis (not presented here) showed that pioneer islands are dominated by vegetation ranging between 3 and 5 years, young island by plants aged between 5 and 15, whereas stable islands are vegetated by trees older than 15 years. The oldest plant, identified in the reach under consideration, can be dated back 33 years.

With reference to the long-term morphological evolution of the Piave River, it has been already reported that the study reach suffered from intense and multiple human impacts (Comiti et al. [19]) which caused substantial active channel narrowing and incision occurred during most of the twentieth century. Within this context, the dynamics of islands is certainly influenced by the factors determining the long-term channel narrowing and incision and the recent widening (Comiti et al. [19]). The narrowing trend (1950 up to 2000), coupled with the lack of flood events capable of changing the size of channels, certainly enhance the chance of island to become stable, and this explain the increase of reduction of active channel (via floodplain vegetation growing and the merge of stable islands with floodplains), the increase of stable island, and the reduction of pioneer island (becoming progressively young than stable islands). Even though a general channel widening is apparent in the study reach between 1999 and 2006, no clear indications of a widespread, concomitant aggradation phase are observed. The extreme 1966 event (RI of 280 years) reduced the island-tochannel area ratio to its lowest values, which then soared in concomitance with channel narrowing and bed incision. Subsequently, floods in 1993 and 2002 (RI of 12 years) determined relevant drops in island cover as well as erosion of marginal vegetation. These observations match with those of Bertoldi et al. [20] 
in the Tagliamento River, a braided river similar for many aspects to the Piave River, but featuring virtually unregulated flows and sediment regimes. In fact, in the Tagliamento River the island dynamics were found to be strictly associated to the occurrence of major floods (RI $>10-15$ Years), which are the only ones able to determine substantial island erosion.

\section{Acknowledgements}

This research was funded by the UNIPD Strategic Project "GEORISKS, Geological, morphological and hydrological processes: monitoring, modeling and impact in the North-Eastern Italy", Research Unit STPD08RWBY-004.

\section{References}

[1] Ward J.V., Tockner K., Edwards P.J., Kollmann J., Bretschko G., Gurnell A.M., Petts G.E. and Rossaro B., 1999. A reference river system for the alps: the Fiume Tagliamento. Regulated rivers: Research \& Management, 15: 63-75.

[2] Osterkamp WR., 1998. Processes of fluvial island formation, with examples from Plum Creek, Colorado and Snake River, Idaho. Wetlands 18: 530-545.

[3] Gurnell A.M., Petts G.E., Hannah D.M., Smith B.P.G., Edwards P.J., Kollmann J., Ward J.V. and Tockner K. 2001. Riparian vegetation and island formation along the gravel-bed Fiume Tagliamento, Italy. Earth Surf. Processes and Landforms, 26: 31-62.

[4] Arscott, D.B., K. Tockner, and J.V. Ward, 2000. Aquatic habitat diversity along the corridor of an Alpine floodplain river (Fiume Tagliamento, Italy), Archiv für Hydrobiologie, 149, 679-704.

[5] Van der Nat, D., K. Tockner, P.J. Edwards, J.V. Ward, and A.M. Gurnell, 2003. Habitat change in braided flood plains (Tagliamento, NE-Italy), Freshwater Biology, 48, 1799- 1812.

[6] Stanford, J.A., J.V. Ward, W.J. Liss, C.A. Frissell, R.N. Williams, J.A. Lichatowich, and C.C. Coutant, 1996. A general protocol for restoration of regulated rivers, Regulated Rivers: Research \& Management, 12, 391-413.

[7] Leopold L.B., Wolman M.G., Miller J.P., 1964. Fluvial processes in Geomorphology. Freeman; San Francisco, USA.

[8] Kellershals R., Asce M., Church M. and Bray D.I., 1976. Classification and Analysis of River Processes. Journal of the Hydraulics Division, July 1976.

[9] Gurnell A.M. e Petts G.E. 2002. Island-dominated landscapes of large floodplain rivers, a European perspective. Freshwater Biology 47: 581-600.

[10] Bathurst J. C., Amezaga J., Cisneros F., Novillo M., Iroumé A., Lenzi M. A., Mintegui J., Urciuolo A., 2010. Forests and floods in Latin America Science, management, policy and the EPIC FORCE project. Water Int. 35, 114-131.

[11] Wyrick J. R., 2005. On the formation of fluvial islands. PhD Thesis, Oregon State University, USA. 
[12] Surian N., 1999. Channel changes due to river regulation: the case of the Piave River, Italy. Earth Surface Processes and Landforms 24: 1135-1151.

[13] Da Canal M., 2011. Analisi della dinamica passata ed attuale del fiume Piave nel Vallone Bellunese finalizzata alla gestione integrata del suo corridoio fluvial. PhD Thesis, University of Padova, pp.213.

[14] Edwards, P. J., J. Kollman, A. Gurnell, G. E. Petts, K. Tockner, and J. V. Ward. 1999. A conceptual model of vegetation dynamics on gravel bars of a large alpine river. Wetlands Ecology and Management 7:141-153.

[15] Kollmann, J. Vieli, M. Edwards, P.J. Tockner K. and Ward J.V., 1999. Interactions between vegetation development and island formation in the Alpine river Tagliamento, Applied Vegetation Science 2, 25-3.

[16] Zanoni L., Gurnell A., Drake N., Surian N., 2008. Island dynamics in a braided river from analysis of historical maps and air photographs. River Research and Applications, 24, 1141-1159.

[17] Picco L., Mao L., Rigon E., Moretto J., Ravazzolo D., Delai F. and M. A. Lenzi, 2012. Riparian forest structure, vegetation cover and floods events in the Piave River (Northeast of Italy). This volume, pp.11.

[18] Surian N., Ziliani L., Comiti F., Lenzi M. A., Mao L., 2009. Channel adjustments and alteration of sediment fluxes in gravel-bed rivers of northeastern Italy: potentials and limitations for channel recovery. River Research and Applications 25, 551-567.

[19] Comiti F., Da Canal M., Surian N., Mao L., Picco L., M. A. Lenzi, 2011. Channel adjustments and vegetation cover dynamics in a large gravel bed river over the last 200 years. Geomorphology 125, 147-159.

[20] Bertoldi, W., Gurnell A., Surian N., Tockner K., Ziliani L., Zolezzi G., 2009. Understanding reference processes: linkages between river flows, sediment dynamics and vegetated landforms along the Tagliamento River, Italy. River Research and Applications 25, 501-516. 